\title{
Review on Enterprise Growth Theories
}

\author{
Huiyuan Mao \\ Tourism and Geography Science College, Shenyang University \\ Shenyang 110044, China \\ Tel: 86-24-2389-4862Ｅ-mail: maohuiyuan2004@126.com
}

\begin{abstract}
The research is financed by the Liaoning Provincial Society and Science Fund (No. 2008LSLKTGLX-92). (Sponsoring information)
\end{abstract}

\begin{abstract}
Through defining and analyzing the meanings of enterprise growth and enterprise growthiness, the existing theoretical results about the enterprise growth were expounded, abstracted and evaluated from different views, which is expected to further provide theoretical references and supports to study the problem of enterprise growth.
\end{abstract}

Keywords: Enterprise, Growthiness, Growth theory

As the economic globalization and the process of system marketization go on, the competition in the global market becomes increasingly intense. Taking US with strong enterprise energy and competitive force as the example, in 100 strongest enterprises listed in Forbes in 1978, there were three of them to be bankrupted, and 35 of them to be purchased, and 30 of them which could not enter into the 100 strongest enterprises list of Forbes in 2006, and only 32 of them to be still on the list. In this period, $68 \%$ of past winners were eliminated from the list. It is obvious that the intense market competition and the survival press were so strong.

This kind of structure change of the international environment has largely changed the survival and growth environment of enterprises in the various regions all over the world, which promotes them more quickly to seek new growth and transformation way, so the new tendency of world enterprise growth and transformation has been formed. The theoretical researches are the base of practical researches, so to better accomplish the researches about the enterprise growth, the systematic analysis and induction of existing foreign and domestic enterprise growth theories are made in the article.

\section{Enterprise growth and enterprise growthiness}

\subsection{Meanings of enterprise growth}

The enterprise growth is used to describe a development process of enterprise from small to big and from weak to strong. The meanings of development exceeds the meanings of growth, and it includes not only the growth process of things, but the generation stage growing out of noting before growth and the periodic process of the stage, i.e. the cycle process going round and round. However, the enterprise growth is a complex adjustment process which is different to the simple scale extension. It takes the balance adjustments of various relations in the interior and the exterior of the enterprise as the essential character, and it is the process of balanced development from unbalance to balance, and from lower balance to higher balance. Therefore, the meanings of enterprise growth is the development process that enterprise keeps the tendencies of balanced and stable growth of total performance level (including output, sales volume, profit and asset gross) or keeps realizing the large enhancement of total performance and the stage spanning of development quality and level (Sun, 2004, P.66-69). In the meanings of enterprise growth, following three connotations are contained.

(1) The time property of enterprise growth. The premise to analyze the growth of enterprise is long period in which the long-term development tendency and process of enterprise are observed, and it is not the status of enterprise in certain time point.

(2) The dynamic property of enterprise growth. The growth of enterprise is not a stable process without troubles. In the growth process, enterprise always transits from balance to unbalance, and the result is to transit from unbalance to balance and from lower balance to higher balancer through unbalance. 
(3) The enterprise growth is the unification of quantity and quality. The increase of quantity is embodied in the extension of enterprise scale such as the increases of sales volume, market share, production value, profit and employee. And the growth of quality is embodied in the enhancement of enterprise quality, which includes the technological innovation ability from immature to mature production technology, the optimal efficiency of investment and output, the organizational innovation and reform.

\subsection{Enterprise growthiness}

The growthiness of enterprise means the ability of enterprise to grow continually, quickly and healthily. Concretely speaking, the enterprise growthiness is the value-added ability obtained by the enterprise through the optimization of the change speed between production factor and production result in the development process, which is represented by that the enterprise and the relative industry have the development property, the product foreground is wide, the enterprise scale is extending year by year, and the management benefit increases continually. The research of enterprise growthiness should centralize in the growth ability of enterprise, and this ability should include practical development ability and growth potential. High growth rate is only the exterior representation of the enterprise with high growth character, and the enterprise with high growth rate in some aspects uncertainly has high growthiness. Furthermore, the growth speed is only one aspect to measure the enterprise growthiness, and the enterprise growthiness should also be analyzed completely, systematically and comprehensively from others angles such as efficiency and competition advantage.

The enterprise growthiness includes two aspects at least. The first one is the survival ability of enterprise. In the intensive market competition, the base of sustainable growth for enterprise is the survival ability of enterprise, and the generation of survival ability depends on the new technology, new product and new originality possessed by the enterprise when it is founded, which can make the enterprise to possess future wider space the competition advantage. The second one is the sustainable development ability of enterprise. After the generation period, the enterprise survives in the market in virtue of its special survival ability, and whether the enterprise faces favorable circumstance or adversity, it can possess the sustainable development ability to exceed itself and keep developing. Therefore, the enterprise growthiness should be considered from multiple angles and layers, and it can not be simply concluded as the character in certain one aspect in the development process of enterprise.

\section{Foreign relative theory researches about enterprise growth}

British management professor, Penrose's Enterprises Growth Theories published in 1959 established the base of the enterprise growth theory. Thereafter, the enterprise growth theory has been concerned by the economics academe and the management theory academe. Up to now, three theoretical opinions have been formed in foreign researchers about the enterprise growth theory, i.e. the growth theory based on the scale boundary theory, the growth theory based on the lifecycle, and the growth theory based on gene combination.

\subsection{The enterprise growth theory based on the scale boundary theory}

In these researches about the enterprise growth theory, the scale boundary theory is very important. The enterprise growth theory includes multiple analysis angels and concept systems. First, various researches hold different concepts of growth, so the diversification of analyzing growth status scale is generated. Second, there are many opinions to describe the curve and growth rate of the growth status. Third, the opinions about the growth mechanism including the growth drive and reason of enterprise are also different. In addition, most above growth theories review the enterprise growth from the economic view. The enterprise growth theory based on the scale boundary is based on Coase's (1937) transaction cost theory. Coase thought that the marketable character of enterprise is the substitute of the price mechanism. Coase utilized the concept of transaction cost to explain the reason of enterprise generation and define the scale. His opinion when discussing the enterprise scale was that when the added transaction was organized by the enterprise, the scale of the enterprise would be extended, and it was organized by another enterprise or the market, the scale of the enterprise didn't be changed, and when the scale of the enterprise is extended, the added transaction cost in the enterprise equaled the cost to accomplish this transaction in the market or the cost of the added transaction organized by another enterprise.

\subsection{The enterprise growth theory based on the lifecycle theory}

In the late of 1980 s, some foreign monographs begun to review the enterprise growth from the survival and development view of the living enterprise, which regarded the enterprise as a life body to dynamically evaluate the characters and countermeasures in various stages of enterprise growth. The representative books included Ichak Adizes's "Enterprise Life Cycle (1988)"and Arie de Gues' "The Living Company (1996)". In the "Enterprise Life Cycle", the enterprise was assimilated to the life body, and the life cycle theory thought that as the life body would go through the life course from born, growth to death, the enterprise would also experience the process from generation, growth, aging and death. As the flexibility of enterprise gradually decreases and the controllability of enterprise gradually increases and decreases, the enterprise growth can be divided into the growth stage, the regeneration and 
mature stage, and the aging stage. The growth stage includes gestation stage, infant stage and step-learning stage. The regeneration and mature stage includes youth stage and prime stage. The aging and death stage includes stabilization stage, noble stage, early bureaucracy stage, bureaucracy stage and death. The character changes of various stages in the lifecycle of enterprise essentially reflect the change of enterprise culture, and to keep lively enterprise culture and flexible organization structure is very important in this theory. The book of "The Living Company" put forward to distinguish the "life company" which was managed for the survival and the "economic company" which was managed for the profit.

\subsection{The enterprise growth theory based on the gene combination theory}

For this theory, the most representative book is Francsi J Gouillart and James N Kelly's "Business Transformation (1988)". In this book, the enterprise was regarded as the organism, and various influencing factors on the enterprise were looked upon genes and chromosomes, which presented a special view. The concept of "Biological Corporation" was proposed in the book, and the eternal life of the life body, "Biological Corporation", rested with that whether it had the ability to drive all systems to transform synchronously, and describe these systems, i.e. "twelve biological corporation systems". The business transformation theory thought that the role of the leader was the gene engineer of "Biological Corporation". Just like the organism, because of the tiny mistake of DNA reproduction, certain gene will mutate, and the result of this mutation may be good or bad, and maybe this mutation just limits the theoretical base shape which induces last bad private enterprise growth and makes the individual develop to good direction. Therefore, the environment change doesn't means good or bad, and the key problem is that the change means opportunity or threat for the "Biological Corporation", i.e. the enterprise. So the transformation of "Biological Corporation" should be the transformation of various systems together.

\section{Chinese relative theory researches about enterprise growth}

In the book of "Enterprise Growth Theory", Yang Du (1996) developed Penrose's enterprise growth theory, started from the concept of management resource, and induced "the general rule of the enterprise growth irrelative with nationality" through analyzing the quantity, extension, structure and dominant subject of the management resource (Yang, 1996).

Based on Yang Du's 2D enterprise growth mode theoretical model, Zhang Lin'ge (1998) absorbed the research results of modern competitive theory, and established the 3D enterprise growth theoretical model (Zhang, 1998, P.45-49), i.e. Yang Du's 2D enterprise growth mode theoretical model was extended from 2D to 3D, and the enterprise growth was analyzed from three angles including scale, diversification and competitive force.

Li Zhicheng and Diao Zhaofeng (2003) put forward the concept of "enterprise growth force" (Li, 2003, P.86-89). They thought that the enterprise growth force means the enterprise's ability and potential to realize the extension of "quantity" and enhance the "quality" in future period, and it decided the probability and development degree of enterprise development.

$\mathrm{Xu}$ Xiaoming and $\mathrm{Xu}$ Zhen (2005) analyzed several kinds of foreign and domestic enterprise growth theory research results based on the view of resource base, discussed five important parts including heterogenic hypothesis, comprehensive knowledge accumulation growth, dynamic competitive advantage of resource, industrial analysis route, and behavior and learning of the modern enterprise growth theory, and analyzed the practical meanings of the theory (Xu, 2005, P.92-99).

Tang Wenxian and Li Panfeng (2005) analyzed the development course of relative enterprise growth theories from three aspects including scale, knowledge and system, and effectively classified the relative enterprise growth theory (Tang, 2005, P.17-21). They pointed out that the enterprise growth was an interactive process with scale extension, knowledge accumulation and system construction.

Starting from the enterprise growth system theory, Wu Aiqi and Jia Shenghua (2007) pointed out three enterprise growth mechanisms existed in the practice, i.e. the interior growth mechanism, the merger growth mechanism and the network growth mechanism, and analyzed the strategic ideas of three growth mechanisms.

In various western theories and opinions about the enterprise growth theory, to analyze the enterprise growth from the scale boundary angle takes Coase's mutual substitution theory of enterprise and market as the start, and the focus is to review the exterior boundary of the enterprise, and to analyze the enterprise growth from the life cycle angle takes the disharmony of the organizational scale extension and the enterprise culture as the start, and the focus is to review the dynamic growth view of the enterprise, and to analyze the enterprise growth from the gene combination angle takes the mutual relation theory of the interior management process and management function as the start, and the focus is to review the interior micro operation mechanism of the enterprise. The domestic researches of the enterprise growth theory experienced initially learning, understanding and present enriching and developing, and one of most prominent characters is that the researchers always use western enterprise growth theories for references and consciously persist in the combination of theoretical research and Chinese practice, so the research direction is more and more clear and the research idea is wider and wider. Based on the enterprise growth theory, it should discuss the enterprise growthiness 
from multiple aspects and angles, which can comprehensively evaluate the growthiness of the growth-type enterprise.

\section{References}

Li, Zhicheng \& Diao, Zhaofeng. (2003). On Business Growth Force and Its Generating Mechanism. Journal of Wuhan University of Technology (Information \& Management Engineering). No.25(5), P. 86-89.

Sun, Xuemin. (2004). The Growth Essence and Ways of the Middle and Small Enterprises. Journal of Zhengzhou University (Philosophy and Social Science Edition), No. 34(4), P. 66-69.

Tang, Wenxian \& Li, Panfeng. (2005). Theory of Firm Growth Based on Three Dimensions. Soft Science, No.19(1), P.17-21.

$\mathrm{Xu}$, Xiaoming \& Xu, Zhen. (2005). Probing into Firm's Growth Theory Based on Resources View. R\&D Management, No. 17(2), P. 92-99.

Yang, Du. (1996). Enterprise Growth Theory. Beijing: China Renmin University Press.

Zhang, Lin'ge. (1998). Theoretical Model of 3D Enterprise Growth Mode. Nankai Economic Studies, No. 5, P.45-49. 